\title{
Microstructure and Properties Evolution of Co-Al-W-Ni-Cr Superalloys by Molybdenum and Niobium Substitutions for Tungsten
}

\author{
HUADONG FU, YUHENG ZHANG, FEI XUE, YI ZHANG, HUAN XU, \\ and JIANXIN XIE
}

\begin{abstract}
The microstructure and mechanical properties of $\mathrm{Co}-\mathrm{Al}-\mathrm{W}$ to $\mathrm{Co}-\mathrm{Al}-\mathrm{Mo} / \mathrm{Nb}$ alloy systems have been investigated in an attempt to identify the influence of replacement for $\mathrm{W}$ in multicomponent Co-based alloys with 30 at. pct $\mathrm{Ni}$ and 12 at. pet $\mathrm{Cr}$. Either Mo or $\mathrm{Nb}$ additions at the expense of $\mathrm{W}$ reduce alloy density to a similar extent. Increasing Mo substitution significantly decreases the $\gamma^{\prime}$ volume fraction and results in spherical $\gamma^{\prime}$ morphology at $750{ }^{\circ} \mathrm{C}$, whereas $\mathrm{Nb}$ substitution shows opposite effects on the $\gamma^{\prime}$ volume fraction and morphology. Accordingly, the $\mathrm{Mo}$ and $\mathrm{Nb}$ additions raise and decrease the microhardness and high-temperature compression strength, respectively. The results can provide reference for the development of Co-based superalloys with low density and high strength.
\end{abstract}

https://doi.org/10.1007/s11661-019-05494-5

(C) The Minerals, Metals \& Materials Society and ASM International 2019

\section{INTRODUCTION}

THE recent report of a $\gamma^{\prime}$-strengthened Co-Al-Wbased alloy opened up a practical possibility for developing new Co-based superalloys, which have become an increasingly active research area over the past decade. ${ }^{[1-13]}$ After studying their potentials, it was found that the solvus temperature of $\gamma^{\prime}$ precipitates can be increased up to $1200{ }^{\circ} \mathrm{C}$ with high solidus temperature, ${ }^{[2-5]}$ mechanical performance $e^{[6-8]}$ and oxidation properties $^{[9-13]}$ as promising engineering materials candidate for high-temperature applications. However, their high density and limited microstructural stability remain the biggest challenges for their further development.

Special efforts have been devoted to reducing or replacing the content of dense but essential $\gamma^{\prime}$-former element W. Some work studied the influence of alloying elements on the density and microstructural stability of Co-based superalloys. ${ }^{\{5,14-20]}$ Neumeier et al. ${ }^{[1]}$ and

HUADONG FU, YUHENG ZHANG, YI ZHANG, HUAN XU, and JIANXIN XIE are with the Beijing Advanced Innovation Center of Materials Genome Engineering, Institute for Advanced Materials and Technology, University of Science and Technology Beijing, Beijing 100083, China. Contact e-mails: hdfu@ustb.edu.cn; jxxie@ mater.ustb.edu.cn FEI XUE is with the Department of Materials Science and Engineering, Northwestern University, 2220 Campus Drive, Evanston, IL, 60208.

Manuscript submitted May 28, 2019.

Article published online October 18, 2019
Knop et al.$^{[22]}$ reported Co-based superalloys with better high-temperature strength than most of polycrystalline Ni-based superalloys, but the density is as high as 8.8 and $8.52 \mathrm{~g} / \mathrm{cm}^{3}$. As a result, variant alloy systems with low or zero $\mathrm{W}$ content have been investigated, developing alloys based on Co-Al-Mo, ${ }^{[23,24]}$ Co-Ge-W, ${ }^{[25,26]}$ Co-Ti-Cr, ${ }^{[27]} \mathrm{Co}-\mathrm{Ti}-\mathrm{V},{ }^{[28]} \mathrm{Co}-\mathrm{Nb}-\mathrm{V},{ }^{[29]}$ and so on. Accordingly, the density has been decreased from 9.5 to $8.5 \mathrm{~g} / \mathrm{cm}^{3}$, close to those of most commercial Ni-based and Co-based polycrystalline alloys. Among these FCC-L1 $1_{2}$ variants, Co-Al-Mo- and Co-Nb-V-based alloys ${ }^{[23,24,29]}$ are mostly investigated; however, in some cases, undesired secondary phases were formed and harmful to the high-temperature mechanical performance. This was especially true when $\mathrm{Cr}$ was added to increase the oxidation resistance but further narrow the $\gamma^{\prime}$ phase field, even when high NI content was added to enlarge the $\gamma-\gamma^{\prime}$ two-phase field and microstructural stability.

In this study, the alloys with intermediate compositions between systems based on Co-Al-W, Co-Al-Mo and $\mathrm{Co}-\mathrm{Al}-\mathrm{Nb}$ have been studied with the presence of high $\mathrm{Cr}$ (12 at. pct) and Ni (30 at. pct) content. The density, phase transformation temperatures, $\gamma-\gamma^{\prime}$ twophase microstructure, long-term microstructural stability and flow stresses at intermediate temperature are examined to understand their change when the $\mathrm{W}$ content is replaced by an equal amount of Mo or $\mathrm{Nb}$. This study will provide insights into the development of low-density, high-strength Co-based superalloys for intermediate temperature applications. 


\section{EXPERIMENTAL MATERIALS AND METHODS}

The nominal compositions of the experimental alloys are given in Table I. Compared with the Co-9Al-5W-30$\mathrm{Ni}-12 \mathrm{Cr}$ (at. pct) alloy, the compositional variants are made using respective $\mathrm{Mo}$ and $\mathrm{Nb}$ as equal replacements for $\mathrm{W}$ in a range of 1 to 4 at. pct. Hence, these alloys are referred to their relevant elemental content as $5 \mathrm{~W}$, $4 \mathrm{~W} 1 \mathrm{Mo}, 3 \mathrm{~W} 2 \mathrm{Mo}, 1 \mathrm{~W} 4 \mathrm{Mo}, 4 \mathrm{~W} 1 \mathrm{Nb}, 3 \mathrm{~W} 2 \mathrm{Nb}$ and $1 \mathrm{~W} 4 \mathrm{Nb}$. Button ingots of $20 \mathrm{~g}$ were prepared by arc melting in an argon atmosphere and turned over eight times for remelting to improve the chemical homogeneity. The actual compositions were measured by a JXA8230 electron probe microanalyzer (EPMA) with $20 \mathrm{kV}$ accelerating voltage and $10 \mathrm{nA}$ beam current after solution heat treatment at $1230{ }^{\circ} \mathrm{C}$ for 24 hours, as listed in Table I.

The samples were encapsulated in quartz tubes, which were subsequently back-filled with pure Ar before solid solution and aging treatments. Similar to the work of Neumeier et al., ${ }^{[21]}$ the solid solution process was set to $1230{ }^{\circ} \mathrm{C} / 24$ hours (air cooling), followed by a two-step heat treatment at $900{ }^{\circ} \mathrm{C} / 24$ hours and $750{ }^{\circ} \mathrm{C} / 12$ hours (air cooling), as a standard heat treatment. An additional long-term heat treatment for 1000 hours at $750{ }^{\circ} \mathrm{C}$ was used to evaluate the microstructure stability.

The microstructure was observed by using a Nikon LV150 metallographic microscope after the polished sample had been etched by hydrochloric acid hydrogen peroxide reagent (proportion of erosion solution: $40 \mathrm{~mL}$ water $+20 \mathrm{~mL}$ hydrochloric acid $+10 \mathrm{~mL}$ hydrogen peroxide). For electron microscope observation, samples were electrolytically etched in an etchant consisting of $42 \mathrm{~mL}$ phosphoric acid, $34 \mathrm{~mL}$ sulfuric acid and $24 \mathrm{~mL}$ water. The $\gamma / \gamma^{\prime}$ microstructure was examined with a Zeiss Ultra 55 field-emission scanning electron microscope (SEM) in secondary electron imaging mode. The INCA X-MAX 50 energy-dispersive X-ray spectroscopy (EDS) equipped to this SEM was used to evaluate the phase compositions. The $\gamma^{\prime}$ volume fraction was analyzed by the standard point count method, and the size of $\gamma^{\prime}$ precipitates (defined as half of the average edge length of the cuboidal precipitates) was measured by the Image-Pro plus 6.0 software. For each alloy, at least five images with the same magnification were used to obtain sufficient statistics for the $\gamma^{\prime}$ volume fraction and size measurement. The density was measured by Archimedes' principle. The DSC was used to obtain the $\gamma^{\prime}$ solvus, solidus and liquidus temperatures on a discoid sample with a diameter of $2 \mathrm{~mm}$ and mass of about $50 \mathrm{mg}$. The measurements were from room temperature to $1600{ }^{\circ} \mathrm{C}$ under $\mathrm{Ar}$ atmosphere with a heating rate of $10{ }^{\circ} \mathrm{C} /$ minutes. The Vickers hardness of the alloys was tested by a HXD-1000TM Vickers hardness testing system, with a load of $300 \mathrm{~g}$ and dwell time of 15 seconds. Seven points were taken from different grains of the polished sample to obtain an average hardness value. Compression tests were performed at $750{ }^{\circ} \mathrm{C}$ at a strain rate of $10^{-4} / \mathrm{s}$ on cylindrical compression samples with size of $\Phi 4 \times 5 \mathrm{~mm}$.

\section{RESULTS}

\section{A. Predicted Thermodynamic Properties}

The thermodynamic information of the experimental alloys is evaluated by Pandat software before conducting heat treatments. Table II lists the phase transformation temperatures, indicating that the $\gamma^{\prime}$ solvus temperature is decreased from $993{ }^{\circ} \mathrm{C}$ in alloy $5 \mathrm{~W}$ to $958^{\circ} \mathrm{C}$ in $1 \mathrm{~W} 4 \mathrm{Mo}$ and $943{ }^{\circ} \mathrm{C}$ in $1 \mathrm{~W} 4 \mathrm{Nb}$ as $\mathrm{W}$ is gradually reduced by $\mathrm{Mo}$ and $\mathrm{Nb}$ additions, respectively. This tendency is different from that in quaternary alloys, in which $\mathrm{Mo}$ and $\mathrm{Nb}$ replacement for $\mathrm{W}$ decreased and increased $\gamma^{\prime}$ solvus temperature to different extents. ${ }^{[30-32]}$

Figure 1 shows the predicted isothermal section of Co-9Al-30Ni-12Cr-W as a function of $\mathrm{Mo}$ and $\mathrm{Nb}$ contents at $750{ }^{\circ} \mathrm{C}$. Although $4 \mathrm{~W} 1 \mathrm{Mo}$ with 1 at. pet Mo addition locates in $\gamma-\gamma^{\prime}$ two-phase region, increasing Mo replacement implies reducing $\gamma^{\prime}$ volume fraction and formation of $\mu$ phase in 3W2Mo and 1W4Mo. Similarly, the increasing $\mathrm{Nb}$ substation for $\mathrm{W}$ rises secondary phase $\delta$ and $\mathrm{AlNbNi}_{2}$ in volume fraction in addition to $\mu$ phase. The calculation results suggest decreased the $\gamma-\gamma^{\prime}$ thermostability by the presence of secondary phases with $\mathrm{Mo}$ and $\mathrm{Nb}$ replacements. According to above calculation, the predicted phase constituent of the experimental alloys at $750{ }^{\circ} \mathrm{C}$ is shown in Table II.

\section{B. Density and Phase Transformation Temperature}

Figure 2 shows the density of the experimental alloys. Replacing W with Mo and Nb significantly reduced the mass density from about $8.9 \mathrm{~g} / \mathrm{cm}^{3}$ in $5 \mathrm{~W}$ to $8.40 \mathrm{~g} / \mathrm{cm}^{3}$ in $1 \mathrm{~W} 4 \mathrm{Mo}$ and $8.29 \mathrm{~g} / \mathrm{cm}^{3}$ in $1 \mathrm{~W} 4 \mathrm{Nb}$. The substitution of 1 at. pct Mo for 1 at. pct W approximately lowers the alloy density by around $0.11 \mathrm{~g} / \mathrm{cm}^{3}$, slightly less than $\mathrm{Nb}$ by about $0.15 \mathrm{~g} / \mathrm{cm}^{3}$. The density of $1 \mathrm{~W} 4 \mathrm{Mo}$ and $1 \mathrm{~W} 4 \mathrm{Nb}$ are close to the recent reported low-density Co-based alloys Co-Al-Mo, Co-Ti-Cr, Co-Ti-V, $\mathrm{C}-\mathrm{Nb}-\mathrm{V},{ }^{[25-29]}$ etc. and commercial Co- and Ni-based alloys IN718, U720Li, etc. for turbine disk application.

The phase transformation temperature measured by DSC are included in Table II, together with predicted values. Alloy $5 \mathrm{~W}$ shows a $\gamma^{\prime}$ solvus temperature of $973{ }^{\circ} \mathrm{C}$, which steadily drops to $949{ }^{\circ} \mathrm{C}$ in $3 \mathrm{~W} 2 \mathrm{Mo}$ as W content reduces. Unlike Mo replacement, $\mathrm{Nb}$ additions continuously raises the $\gamma^{\prime}$ solvus temperature from $996{ }^{\circ} \mathrm{C}$ in $4 \mathrm{~W} 1 \mathrm{Nb}$ to $1035^{\circ} \mathrm{C}$ in $1 \mathrm{~W} 4 \mathrm{Nb}$. Compared to the thermodynamic calculation, although the trend of decreasing $\gamma^{\prime}$ solvus temperature by Mo replacement for $\mathrm{W}$ is in agreement with the prediction (Table II), the actual values are at least $20{ }^{\circ} \mathrm{C}$ smaller. The measured increasing $\gamma^{\prime}$ solvus temperature with increasing $\mathrm{Nb}$ is obviously inconsistence with the calculation, which exhibits an even lowering accuracy perdiction of the thermodynamic properties for the Nb-containing alloys than that of Mo. The significant difference between prediction and experimental results in $\gamma^{\prime}$ solvus temperature may be from the limited thermodynamic data input for $\mathrm{Mo}$ - and $\mathrm{Nb}$-containing multicomponent Co-base alloys. 
Table I. Nominal and Measured Compositions by Electron Probe Microanalyzer (EPMA) of Experimental Alloys (Atomic Percent)

\begin{tabular}{|c|c|c|c|c|c|c|c|c|}
\hline Alloy & Composition & $\mathrm{Co}$ & $\mathrm{Al}$ & W & $\mathrm{Ni}$ & $\mathrm{Cr}$ & Mo & $\mathrm{Nb}$ \\
\hline \multirow[t]{2}{*}{$5 \mathrm{~W}$} & nominal & 44 & 9 & 5 & 30 & 12 & - & - \\
\hline & actual & 44.04 & 8.86 & 5.07 & 29.71 & 12.32 & - & - \\
\hline \multirow[t]{2}{*}{ 4W1Mo } & nominal & 44 & 9 & 4 & 30 & 12 & 1 & - \\
\hline & actual & 44.07 & 8.90 & 3.92 & 29.49 & 12.58 & 1.04 & - \\
\hline \multirow[t]{2}{*}{$3 \mathrm{~W} 2 \mathrm{Mo}$} & nominal & 44 & 9 & 3 & 30 & 12 & 2 & - \\
\hline & actual & 44.22 & 8.91 & 3.09 & 29.89 & 12.10 & 1.79 & - \\
\hline \multirow[t]{2}{*}{ 1W4Mo } & nominal & 44 & 9 & 1 & 30 & 12 & 4 & - \\
\hline & actual & 43.81 & 9.05 & 1.25 & 29.69 & 12.42 & 3.78 & - \\
\hline \multirow[t]{2}{*}{$4 \mathrm{~W} 1 \mathrm{Nb}$} & nominal & 44 & 9 & 4 & 30 & 12 & - & 1 \\
\hline & actual & 43.76 & 9.03 & 4.07 & 29.91 & 12.19 & - & 1.04 \\
\hline \multirow[t]{2}{*}{$3 \mathrm{~W} 2 \mathrm{Nb}$} & nominal & 44 & 9 & 3 & 30 & 12 & - & 2 \\
\hline & actual & 44.41 & 8.69 & 3.09 & 29.89 & 12.11 & - & 1.81 \\
\hline \multirow[t]{2}{*}{$1 \mathrm{~W} 4 \mathrm{Nb}$} & nominal & 44 & 9 & 1 & 30 & 12 & - & 4 \\
\hline & actual & 43.83 & 9.05 & 1.26 & 29.69 & 12.43 & - & 3.74 \\
\hline
\end{tabular}

Table II. Calculated and DSC Measured Phase Transformation Temperatures

\begin{tabular}{|c|c|c|c|c|c|}
\hline Alloy & Alloy & $\gamma$ Solvus & Solidus & Liquids & Phase Equilibrium at $750{ }^{\circ} \mathrm{C}$ \\
\hline \multirow[t]{2}{*}{$5 \mathrm{~W}$} & calculated & 993 & 1415 & 1445 & $\gamma+\gamma^{\prime}+\mu$ \\
\hline & actual & 973 & 1415 & 1440 & $\gamma+\gamma^{\prime}$ \\
\hline \multirow[t]{2}{*}{ 4W1Mo } & calculated & 980 & 1404 & 1411 & $\gamma+\gamma^{\prime}$ \\
\hline & actual & 964 & 1409 & 1433 & $\gamma+\gamma^{\prime}$ \\
\hline \multirow[t]{2}{*}{$3 \mathrm{~W} 2 \mathrm{M} 0$} & calculated & 977 & 1396 & 1434 & $\gamma+\gamma^{\prime}+\mu$ \\
\hline & actual & 949 & 1410 & 1433 & $\gamma+\gamma^{\prime}$ \\
\hline \multirow[t]{2}{*}{ 1W4Mo } & calculated & 958 & 1380 & 1424 & $\gamma+\gamma^{\prime}+\mu$ \\
\hline & actual & - & 1390 & 1419 & $\gamma+\gamma^{\prime}$ \\
\hline \multirow[t]{2}{*}{$4 \mathrm{~W} 1 \mathrm{Nb}$} & calculated & 979 & 1358 & 1432 & $\gamma+\gamma^{\prime}+\mu$ \\
\hline & actual & 996 & 1380 & 1422 & $\gamma+\gamma^{\prime}$ \\
\hline \multirow[t]{2}{*}{$3 \mathrm{~W} 2 \mathrm{Nb}$} & calculated & 964 & 1316 & 1410 & $\gamma+\gamma^{\prime}+\mu$ \\
\hline & actual & 1005 & 1342 & 1403 & $\gamma+\gamma^{\prime}$ \\
\hline \multirow[t]{2}{*}{$1 \mathrm{~W} 4 \mathrm{Nb}$} & calculated & 943 & 1241 & 1373 & $\gamma+\gamma^{\prime}+\delta$ \\
\hline & actual & 1035 & 1274 & 1370 & $\gamma+\gamma^{\prime}$ \\
\hline
\end{tabular}

The predicted phase equilibrium at $750{ }^{\circ} \mathrm{C}$ and phase constitute after aging at $750{ }^{\circ} \mathrm{C}$ for $1000 \mathrm{~h}$ are also included.
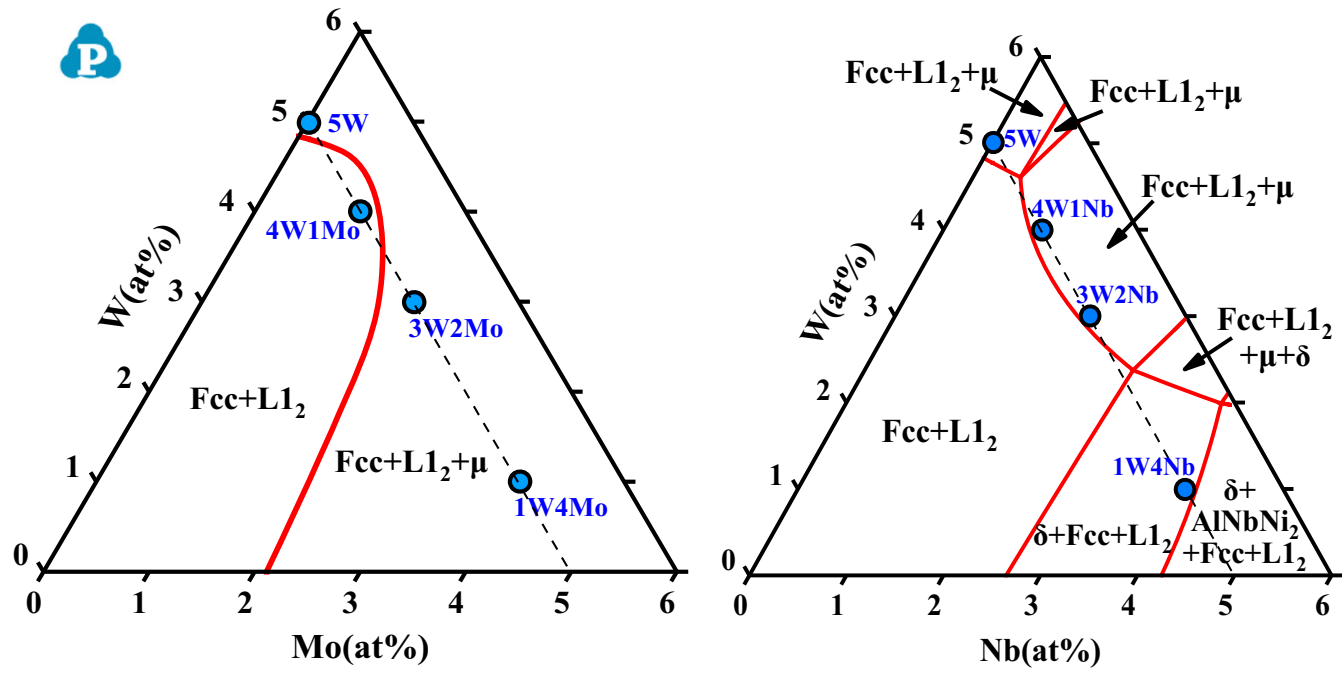

Fig. 1 - Calculated phase diagram of experimental alloys. 


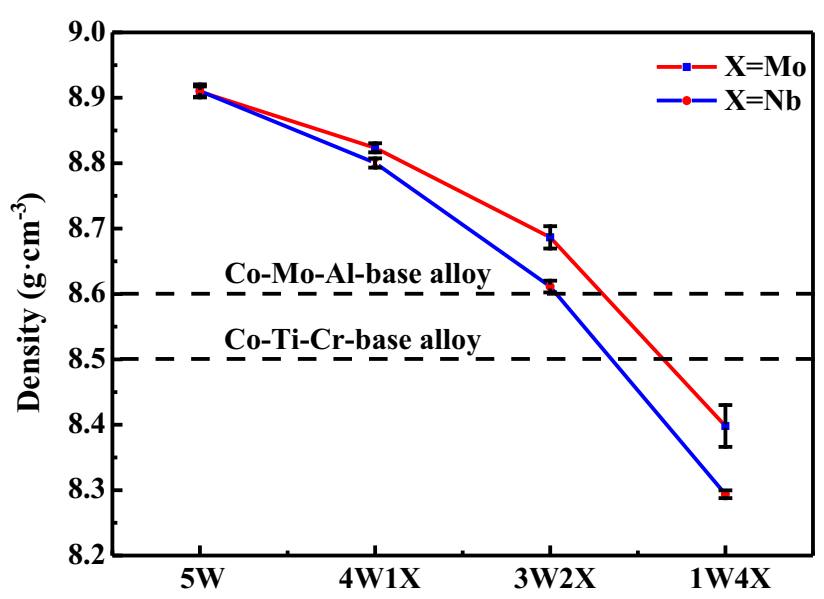

Fig. 2-Density of experimental alloys together with some reported Co-base alloys ${ }^{[24,27]}$

Both $\mathrm{Mo}$ and $\mathrm{Nb}$ replacements decrease the actual solidus temperatures. The Mo replacement slightly reduce it from $1415^{\circ} \mathrm{C}$ in $5 \mathrm{~W}$ to $1390{ }^{\circ} \mathrm{C}$ in $1 \mathrm{~W} 4 \mathrm{Mo}$, but $\mathrm{Nb}$ additions strongly lower it to $1274{ }^{\circ} \mathrm{C}$ in $1 \mathrm{~W} 4 \mathrm{Nb}$. It implies a significant narrowed processing window, i.e. temperature difference between $\gamma^{\prime}$ solvus and solidus, for the experimental alloys as potencial disk materials, by about $45^{\circ} \mathrm{C}$ for 1 at. pct $\mathrm{Nb}$ replacement for W. Similar to the solidus temperature, both Mo and $\mathrm{Nb}$ decrease the liqudus temperature, and $\mathrm{Nb}$ exhibits a greater influence.

\section{Cast Microstructure}

Figure 3 shows the as-cast microstructure of the experimental alloys, which exhibit the similar dendritic microstructure after solidification. A small amount of eutectic structure is found in alloy $5 \mathrm{~W}$ at interdendritic regions. The similar eutectic structure is detected in 4W1Mo but slightly decreases in volume fraction (Figure 3(b)), and it disappears with higher levels of Mo replacement in 4W2Mo and 1W4Mo (Figures 3(d) and (f)). In contrast, increasing $\mathrm{Nb}$ content promotes interdendritic eutectic structure with increasing volume fraction (Figures 3(c), (e) and (g)). The composition of eutectic structure in these alloys is analyzed by SEM-EDS and displayed in Table III. It implies that one phase of the eutectic structure in 5W (Figure 3(a)) is enriched in $\mathrm{Al}$, and most likely is $\beta-(\mathrm{Co}, \mathrm{Ni}) \mathrm{Al}$ phase in $\gamma+\beta+\mu$ eutectic. The eutectic structure in $4 \mathrm{~W} 1 \mathrm{Mo}$ exhibits the same chemical characteristics and is probably the same eutectic. Differently, all the bright contrast eutectic phases in alloys $4 \mathrm{~W} 1 \mathrm{Nb}, 3 \mathrm{~W} 2 \mathrm{Nb}$ and $1 \mathrm{~W} 4 \mathrm{Nb}$ show enrichment of $\mathrm{Nb}$ and exhibits the same chemical features as that of Laves- $(\mathrm{Co}, \mathrm{Ni}, \mathrm{Cr})_{2}(\mathrm{Nb}, \mathrm{W})$ phases in $\gamma+$ Laves eutectic. ${ }^{[33]}$ Due to the limited size of eutectic structure in experimental alloys, only the phase in $1 \mathrm{~W} 4 \mathrm{Nb}$ alloy is confirmed of C15-Laves type in chemistry by point EDS analysis. The above results show that Mo addition to replace $\mathrm{W}$ may change the solidification path by reducing the segregation of $\mathrm{Al}$ element during solidification, while $\mathrm{Nb}$ replacement appears to change the solidification behavior by promoting the formation of Laves phase.

\section{Microstructure Evolution at $750{ }^{\circ} \mathrm{C}$}

The $\gamma / \gamma^{\prime}$ two-phases microstructures are observed in all experimental alloys except for alloy $1 \mathrm{~W} 4 \mathrm{Mo}$ after aging heat treatment at $900{ }^{\circ} \mathrm{C}$ for 24 hours and $750{ }^{\circ} \mathrm{C}$ for 12 hours, as shown in Figure 4. Compared to $5 \mathrm{~W}$ alloy, the morphology of the $\gamma^{\prime}$ precipiates becames more spherical with the increasing Mo replacement, probably attributed to the decrease of the $\gamma / \gamma^{\prime}$ two-phase misfit as reported in Mo-containing Co-base alloys. ${ }^{[30-32]}$ However, replacing $\mathrm{W}$ with $\mathrm{Nb}$ leading to less spherical $\gamma^{\prime}$ precipiates in $4 \mathrm{~W} 1 \mathrm{Nb}$ (Figure 4) and further cuboidal precipiates in $1 \mathrm{~W} 4 \mathrm{Nb}$. The volume fractions of $\gamma^{\prime}$ precipitates in the experimental alloys are given in Figure 5. It linearly decreases from 35.3 pct in $5 \mathrm{~W}$ to 0 in $1 \mathrm{~W} 4 \mathrm{Mo}$ with the increasing Mo content, while gradually raises to 65.1 pct as the levels of $\mathrm{Nb}$ replacement becomes higher to $1 \mathrm{~W} 4 \mathrm{Nb}$.

After long-term aging at $750{ }^{\circ} \mathrm{C}$ for 1000 hours, the $\gamma^{\prime}$ precipitates coarsen to different degrees in all experimental alloys, and the $\gamma^{\prime}$ morphology become less spherical and more cuboidal in Mo- and Nb-containing alloys, respectively (Figure 4). The $\gamma^{\prime}$ phase morphology in $5 \mathrm{~W}$ and $4 \mathrm{~W} 1 \mathrm{Mo}$ changes from spherical to near cuboidal, and the $\gamma^{\prime}$ morphology of 3W2Mo changed from spherical to near spherical. This shape change indicats that as the $\gamma^{\prime}$ precipitates grow, the shape changes from a $\gamma / \gamma^{\prime}$ two-phase interface to a $\gamma / \gamma^{\prime}$ two-phase coherent strain energy control. With the increasing of $\mathrm{Nb}$, the morphology of the $\gamma^{\prime}$ precipitates changes from nearly cuboidal to cuboidal, most likely due to the relieved $\gamma / \gamma^{\prime}$ interfacial strain, which is consistent with the phenomenon observed in the alloys with the replacement of $\mathrm{W}$ by $\mathrm{Nb}$ after long-term aging.

After aging for 1000 hours, as the $\gamma^{\prime}$ volume fractions raise to different extents to approach thermodynamic equilibrium, the tendency of increasing $\gamma^{\prime}$ volume fraction with increasing $\mathrm{Mo}$ and $\mathrm{Nb}$ replacements seems unchanged. It is remarkable that after the heat treatment at $900{ }^{\circ} \mathrm{C}$ for 24 hours and $750{ }^{\circ} \mathrm{C}$ for 1000 hours, the $\gamma^{\prime}$ phase volume fraction in alloys with the replacement of Mo for W increases more than twice as much as that in alloys with the replacement of $\mathrm{Nb}$ for $\mathrm{W}$. The main reason is probably related to the diffusion rate of Mo, which is slower than that of $\mathrm{Nb}$ comparing the diffusion rate of $\mathrm{Mo}$ and $\mathrm{Nb}$ in Co matrix at $750{ }^{\circ} \mathrm{C} .{ }^{[34]}$ Due to such slower diffusion rate, alloys with the Mo replacement for $\mathrm{W}$ are supposed to deviate from the equilibrium state more than alloys with $\mathrm{Nb}$ replacement after heat treatment at $900{ }^{\circ} \mathrm{C}$ for 24 hours and $750{ }^{\circ} \mathrm{C}$ for 12 hours. After long time aging like 1000 hours heat treatment, the system is approaching to the equilibrium state, and thus the volume fraction of the $\gamma^{\prime}$ precipitates in alloys with the Mo replacement increases more than the alloys with the $\mathrm{Nb}$ replacement. The volume fraction in $5 \mathrm{~W}$ is $48.5 \mathrm{pct}$, which continuously declines to 32.7 pct in $1 \mathrm{~W} 4 \mathrm{Mo}$ with increasing Mo content but raises to 74.4 pct in $1 \mathrm{~W} 4 \mathrm{Nb}$ containing higher content of $\mathrm{Nb}$ (Figure 5). 

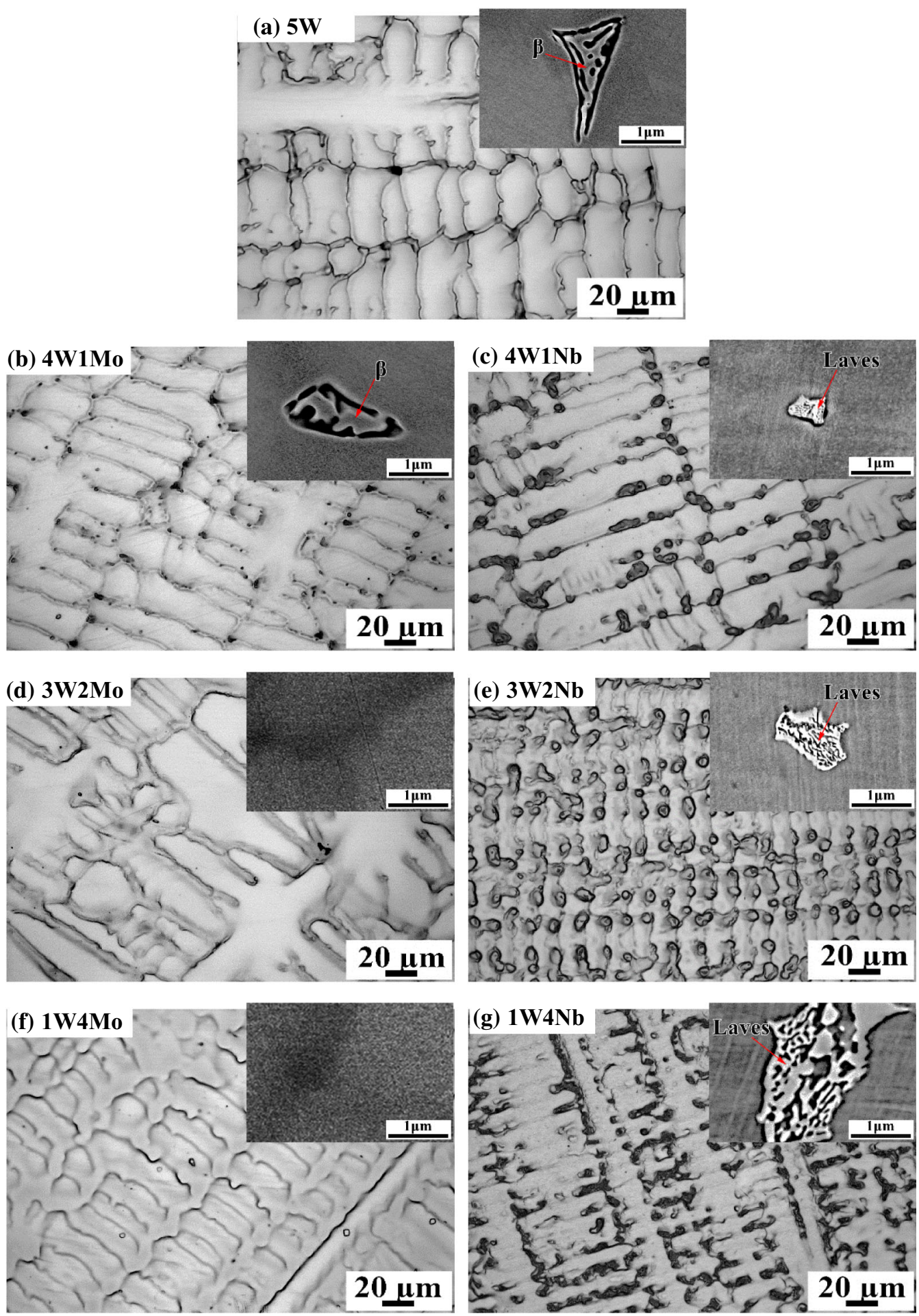

Fig. 3-As-cast microstructure of experimental alloys. (a) 5W, (b) 4W1Mo, (c) 4W1Nb, (d) 3W2Mo, (e) 3W2Nb, (f) 1W4Mo, (g) 1W4Nb.

Figure 4 shows the BSE images at grain boundary of alloys with the replacement of $\mathrm{W}$ by $\mathrm{Mo}$ and $\mathrm{Nb}$ after aging heat treatment of $900{ }^{\circ} \mathrm{C}$ for 24 hours and $750{ }^{\circ} \mathrm{C}$ for 1000 hours. Limited number of bright contrast blocky precipitates are observed at grain boundary in $5 \mathrm{~W}$. The increasing Mo seems to negligibly affects the formation of secondary phases with very small amount of bright contrast precipitates at grain boundaries of
$4 \mathrm{~W} 1 \mathrm{Mo}, 3 \mathrm{~W} 2 \mathrm{Mo}$, and $1 \mathrm{~W} 4 \mathrm{Mo}$ ranging from 0.5 to $3 \mu \mathrm{m}$ in size. However, increaseing $\mathrm{Nb}$ replacement promotes the size of secondary precipiates up to 5 to $10 \mu \mathrm{m}$ in $1 \mathrm{~W} 4 \mathrm{Nb}$ despite the similar low level of secondary phase.

The SEM-EDS analysis are shown in Table IV. The bright precipitates in $5 \mathrm{~W}, 4 \mathrm{~W} 1 \mathrm{Mo}, 3 \mathrm{~W} 2 \mathrm{Mo}$, and $1 \mathrm{~W} 4 \mathrm{Mo}$ alloys are probably $\mu-(\mathrm{Co}, \mathrm{Ni})_{7}(\mathrm{Cr}, \mathrm{Mo}, \mathrm{W})_{6}$ 
Table III. SEM-EDS Results of Interdendritic Phase After Solidification in Experimental Alloys (Atomic Percent)

\begin{tabular}{lccrccl}
\hline Alloys & Co & Ni & Al & W & Cr & Mo/Nb \\
\hline $5 \mathrm{~W}$ & 40.40 & 30.00 & 15.99 & 1.86 & 11.75 & 0 \\
$4 \mathrm{~W} 1 \mathrm{Mo}$ & 37.39 & 32.07 & 14.91 & 3.42 & 11.69 & 0.51 \\
4W1Nb & 38.98 & 23.69 & 3.94 & 2.72 & 10.36 & 20.30 \\
3W2Nb & 38.04 & 25.34 & 5.96 & 1.91 & 8.41 & 20.33 \\
1W4Nb & 38.56 & 25.12 & 4.97 & 0.80 & 8.40 & 22.15 \\
\hline
\end{tabular}

phase, one of the topologically close-packed phases (TCP). The increasing Mo additions seems to have negligible effects on the formation of secondary phases. The secondary phase precipitates in $3 \mathrm{~W} 2 \mathrm{Nb}$ and $1 \mathrm{~W} 4 \mathrm{Nb}$ alloys are probably $\delta-(\mathrm{Co}, \mathrm{Ni})_{3} \mathrm{Nb}$ or $\gamma^{\prime \prime}-(\mathrm{Co}, \mathrm{Ni})_{3}$ $\mathrm{Nb}$, which have the same nominal composition. Through comparative analysis, $4 \mathrm{~W} 1 \mathrm{Nb}$ with 1 at. pct $\mathrm{Nb}$ has the best high long-term microstructural stability, as excessive $\mathrm{Nb}$ element content leads to the precipitation of $\delta-(\mathrm{Co}, \mathrm{Ni})_{3} \mathrm{Nb}$ at the grain boundary.

\section{E. Mechanical Property}

Figure 6 shows the room-temperature Vickers hardness of the experimental alloys after solidification and aging treatment. The hardness in as-cast condition is significantly lower than that in both 12 and 1000 hours aging conditions, indicating that formation of $\gamma-\gamma^{\prime}$ two-phase mcrostructure apparently improves the resistance to deform. With the extension of aging time to 1000 hours at $750{ }^{\circ} \mathrm{C}$, the hardness of the experimental alloys with Mo replacement shows an increasing trend than 12-hour-aged alloys, most likely due to the slightly increasing $\gamma^{\prime}$ volume fraction and cuboidal morphology, whereas negligible difference is found in $\mathrm{Nb}$-containing alloys with the same increasing $\gamma^{\prime}$ volume fraction. After the same aging time, Mo replacement reduces the hardness, while $\mathrm{Nb}$ replacement increases it. For example, after aging at $900{ }^{\circ} \mathrm{C} / 24$ hours $+750{ }^{\circ} \mathrm{C} / 12$ hours, 1 at. pct Mo substitution of $\mathrm{W}$ reduces the hardness of the experimental alloys by $\sim 15 \mathrm{HV}$, while 1 at. pct $\mathrm{Nb}$ substitution of $\mathrm{W}$ increases the hardness by $\sim 13 \mathrm{HV}$.

Figure 7 shows the 0.2 pct compression flow stress of the experimental alloys at $750{ }^{\circ} \mathrm{C}$ after the aging treatment of $900{ }^{\circ} \mathrm{C}$ for 24 hours and $750{ }^{\circ} \mathrm{C}$ for 12 hours. Compared to $5 \mathrm{~W}$, Mo substitution leads to slightly lower compression strength in $4 \mathrm{~W} 1 \mathrm{Mo}$ and $3 \mathrm{~W} 2 \mathrm{Mo}$, in agreement with hardness properties. The flow strength of $1 \mathrm{~W} 4 \mathrm{Mo}$ significantly reduces to $256.8 \mathrm{MPa}$, most likely due to the absence of $\gamma^{\prime}$ precipiates. Instead, $\mathrm{Nb}$ additions make a significant rise of compression strength at $750{ }^{\circ} \mathrm{C}$, because of the 10 to 30 pct higher $\gamma^{\prime}$ phase volume fraction than that in $5 \mathrm{~W}$ alloy (Figure 5). It can be inferred from the morphological evolution of $\gamma^{\prime}$ in Figure 5 that 1 at. pct $\mathrm{Nb}$ substitution of 1 at. pct $\mathrm{W}$ leads to a significant increase in the misfit of $\gamma / \gamma^{\prime}$ phase, and the increase in the lattice strain between $\gamma / \gamma^{\prime}$ phase caused by the significantly increased misfit of $\gamma / \gamma^{\prime}$ phase may also contribute to the increase in strength.

\section{DISCUSSION}

Compared to the conventional Ni-based superalloys, the high density of the novel Co-based superalloys may severely limits their applications in the aerospace industry. The high concentration of $\mathrm{W}$ in the Co-Al-W-based superalloys - typically between 3 and 10 at. pct (10 and $30 \mathrm{wt}$ pct) - is the primary cause of their high mass density. ${ }^{[14]}$ Therefore, assessing the influence of reducing the amount of $\mathrm{W}$ on their microstructure stability and mechanical properties is reasonably necessary. In this experiment, the density of the alloys is significantly reduced with the replacement of $\mathrm{W}$ by $\mathrm{Mo}$ and $\mathrm{Nb}$, as shown in Figure 2.

Superalloys need to service at high temperatures for a long time. Therefore, one of the major concerns for the alloys design is to improve the microstructure stability of the alloys on the premise of acceptable mechanical properties. The mechanical properties of $\gamma^{\prime}$-strengthened alloy phase is closely related to the $\gamma^{\prime}$ composition, morphology and size that affect the stability of $\gamma^{\prime}$ precipitates. In the present alloys, Replacing $\mathrm{W}$ with Mo gradually reduces the hardness and the compression yield strength, whereas the substituitons of $\mathrm{Nb}$ for $\mathrm{W}$ show the opposite effects (Figures 6 and 7). This is because all $\mathrm{W}, \mathrm{Mo}, \mathrm{Nb}$ are $\gamma^{\prime}$-formers, ${ }^{[19]}$ and the first principles calculation results show that in the $\gamma^{\prime}-\mathrm{Co}_{3}(\mathrm{Al}$, $\mathrm{W})$, Mo and $\mathrm{Nb}$ atoms tend to occupy the lattice site of $\mathrm{W}$ atoms, ${ }^{[35]}$ but $\mathrm{Mo}$ and $\mathrm{Nb}$ have different formation ability of $\gamma^{\prime}$ phase. It leads to the results that replacing $\mathrm{W}$ by $\mathrm{Nb}$ increase $\gamma^{\prime}$ volume fraction, while replacing $\mathrm{W}$ by Mo decreases the $\gamma^{\prime}$ volume fraction under the same heat treatment condition. Eventually the variations of the $\gamma^{\prime}$ volume fraction for the alloys result in the opposite effects on the mechanics performance.

As for the microstructure stability, replacing $\mathrm{W}$ by Mo does not inhibit the formation of $\mu-(\mathrm{Co}, \mathrm{Ni})_{7}(\mathrm{Cr}$, $\mathrm{Mo}, \mathrm{W})_{6}$ phase at grain boudnaries after aging at $750{ }^{\circ} \mathrm{C}$ for 1000 hours, as shown in Figure 4. The $\mu$ phase is enriched in W and Mo, which will decrease the solid solution strengthening, and thus may reduce the creep and other mechanical properties of the alloys. However, given the small size and low volume fraction of $\mu$ phase, its influence on the mechanical properties of experimental alloys needs further study. Nevertheless, the results displayed in Figure 4 show that replacing $\mathrm{W}$ by 1 at. pct $\mathrm{Nb}$ can inhibit the formation of $\mu-(\mathrm{Co}, \mathrm{Ni})_{7}(\mathrm{Cr}, \mathrm{Mo}, \mathrm{W})_{6}$ phase, but a higher $\mathrm{Nb}$ content leads to the formation of $\delta$ - $(\mathrm{Co}, \mathrm{Ni})_{3} \mathrm{Nb}$ phase in $3 \mathrm{~W} 2 \mathrm{Nb}$ and $1 \mathrm{~W} 4 \mathrm{Nb}$ alloys. This happens because both Mo and $\mathrm{W}$ are $\mu$-formers, and the total content $((\mathrm{Mo}+\mathrm{W})$ at. pct $=5 \mathrm{pct})$ is not changed by replacing $\mathrm{W}$ with Mo, so the similar forming ability of $\mu$ phase is expected. While replacing $\mathrm{W}$ with $\mathrm{Nb}$ reduces the total content of $\mu$-formers, which, hence, can inhibit the formation of $\mu$ phase in $4 \mathrm{~W} 1 \mathrm{Nb}, 3 \mathrm{~W} 2 \mathrm{Nb}$ and $1 \mathrm{~W} 4 \mathrm{Nb}$ alloys. It is worth noting that the formation of $\mu$ phase may be effectively inhibited when (Mo + $\mathrm{W})$ at. pct $<5$ pct as detected in the $4 \mathrm{~W} 1 \mathrm{Nb}$. After aging at $750{ }^{\circ} \mathrm{C}$ for 1000 hours, the detrimental phase $(\mu$ and $\delta$ ) volume fractions in the experimental alloys are not more than 1 pct, which means that the experimental alloy has good microstructure stability with lowered W 


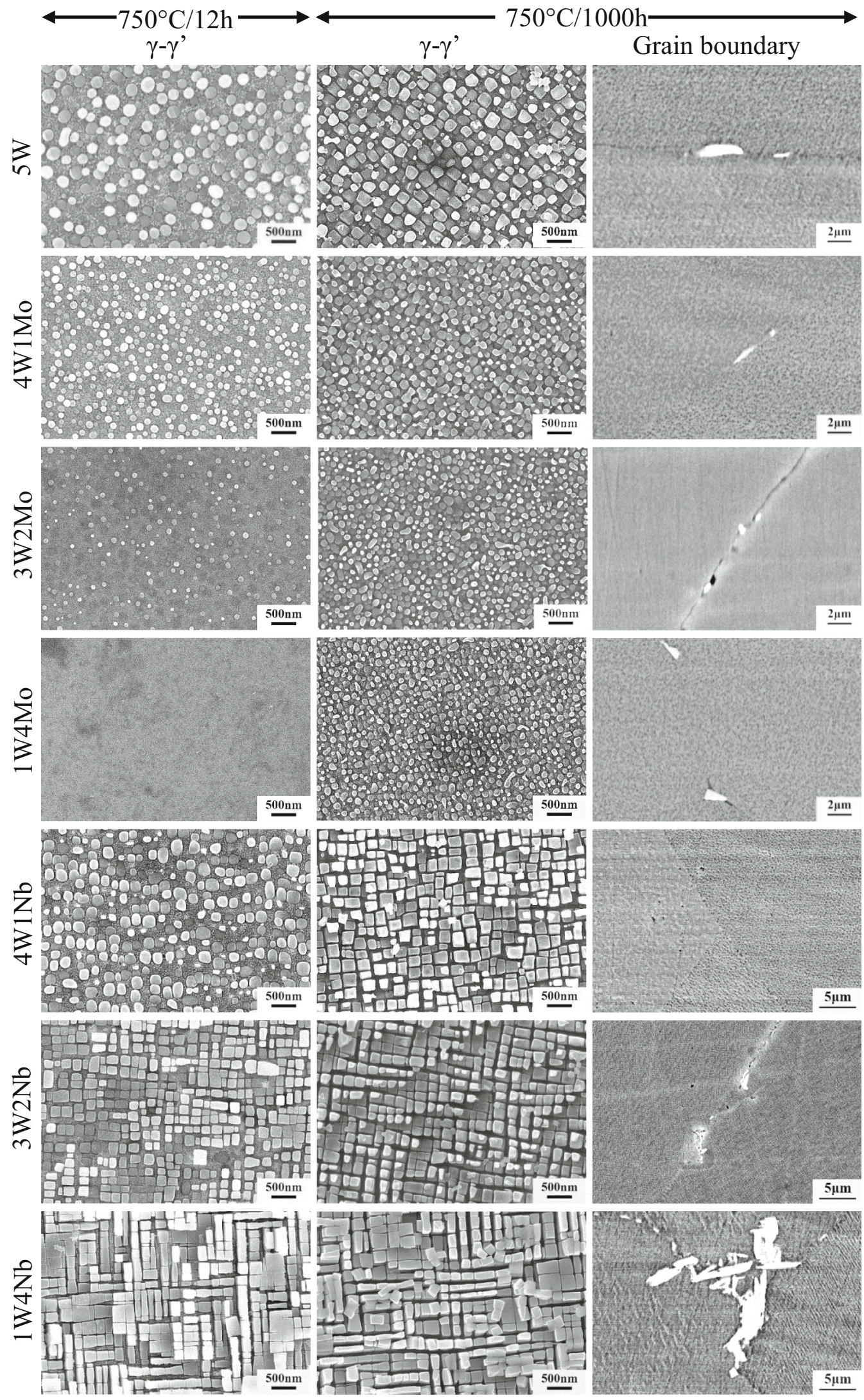

Fig. 4-The microstructures after $900{ }^{\circ} \mathrm{C} / 24 \mathrm{~h}+750{ }^{\circ} \mathrm{C} / 12 \mathrm{~h}$ and $750{ }^{\circ} \mathrm{C} / 1000 \mathrm{~h}$ of experimental alloys. 
content. By controlling the content of $\mathrm{Nb}$ element, the size and volume fraction of $\gamma^{\prime}$ precipitates can be increased while the density is reduced to improve the mechanical properties of the alloy. The microstructure stability of the alloys may be further improved by adding a small amount of Ti and Ta elements to inhibit the formation of the detrimental phases. ${ }^{[18]}$

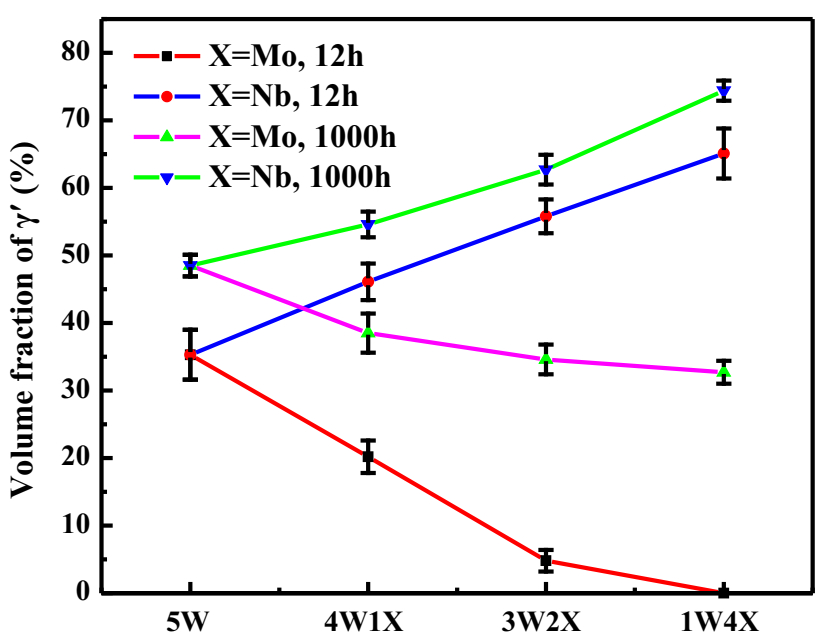

Fig. 5- $\gamma^{\prime}$ volume fraction in experiment alloys after heat treatment at $900{ }^{\circ} \mathrm{C}$ for $24 \mathrm{~h}$ and $750{ }^{\circ} \mathrm{C}$ for $12 \mathrm{~h}$ and $1000 \mathrm{~h}$.

Table IV. SEM-EDS Results of Bright Contrast Precipitate at Grain Boundary After Heat Treatment at $900{ }^{\circ} \mathrm{C} / 24 \mathrm{~h}+750{ }^{\circ} \mathrm{C} / 1000 \mathrm{~h}$ (At. Pct)

\begin{tabular}{lcccccc}
\hline Alloy & $\mathrm{Co}$ & $\mathrm{Ni}$ & $\mathrm{Al}$ & $\mathrm{W}$ & $\mathrm{Cr}$ & $\mathrm{Mo} / \mathrm{Nb}$ \\
\hline 5W & 42.55 & 12.99 & 1.49 & 31.43 & 11.54 & 0 \\
4W1Mo & 33.47 & 15.84 & 3.69 & 18.43 & 19.24 & 9.34 \\
3W2Mo & 41.81 & 16.27 & 3.29 & 15.70 & 11.16 & 11.77 \\
1W4Mo & 39.97 & 12.30 & 1.64 & 4.69 & 9.28 & 32.12 \\
4W1Nb & - & - & - & - & - & - \\
3W2Nb & 46.72 & 24.98 & 0.75 & 8.32 & 8.87 & 10.37 \\
1W4Nb & 44.14 & 27.67 & 1.28 & 1.07 & 2.80 & 23.04 \\
\hline
\end{tabular}

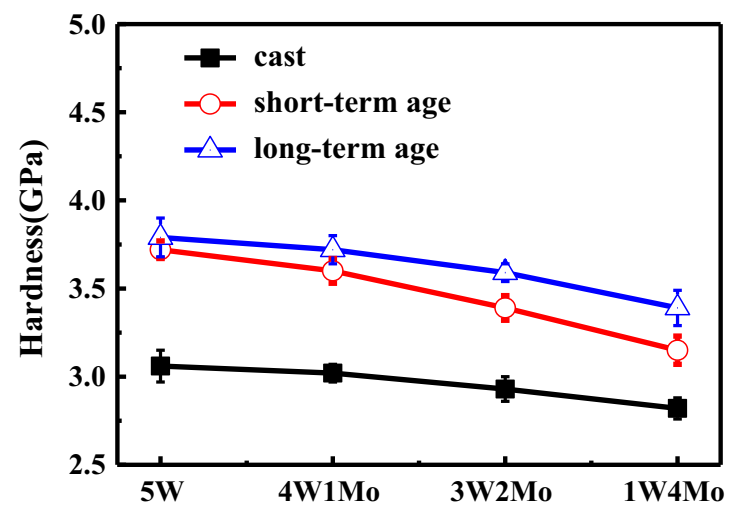

(a)
The coarsening resistance of $\gamma^{\prime}$ precipitates is also an important aspect of the microstructure stability for superalloys. If the $\gamma^{\prime}$ precipitate coarsening is controlled by the diffusion of solutes in the matrix, the precipitate coarsening follows the classical Lifshitz-Slyozov-Wagner (LSW) theory, ${ }^{[36]}$ as shown in Eq. [1].

$$
r^{3}(t)-r_{0}^{3}(t)=\frac{8 D C \Gamma V_{m}}{9 \mathrm{RT}} \mathrm{t}=\mathrm{kt}
$$

where, $r_{0}$ is the initial precipitate radius, $r$ is the instantaneous precipitate radius, $k$ is the coarsening rate coefficient, $\Gamma$ is the surface energy associated with the $\gamma / \gamma^{\prime}$ two phases, and $D=D_{0} \exp (-\mathrm{Q} / \mathrm{RT})$ is the temperature-dependent diffusion coefficient of the rate controlling solute in the matrix, $C$ is the equilibrium atomic fraction of the solute, $V_{\mathrm{m}}$ is the molar volume of the precipitate, $R$ is the ideal gas constant $(8.314 \mathrm{~J} /$ $\mathrm{K} / \mathrm{mol}$ ), $\mathrm{T}$ is the absolute temperature.

As described in Eq. [1], the $\gamma / \gamma^{\prime}$ two-phase interfacial energy $\Gamma$ and the diffusion coefficient of the solutes are the important parameters to influence the coarsening

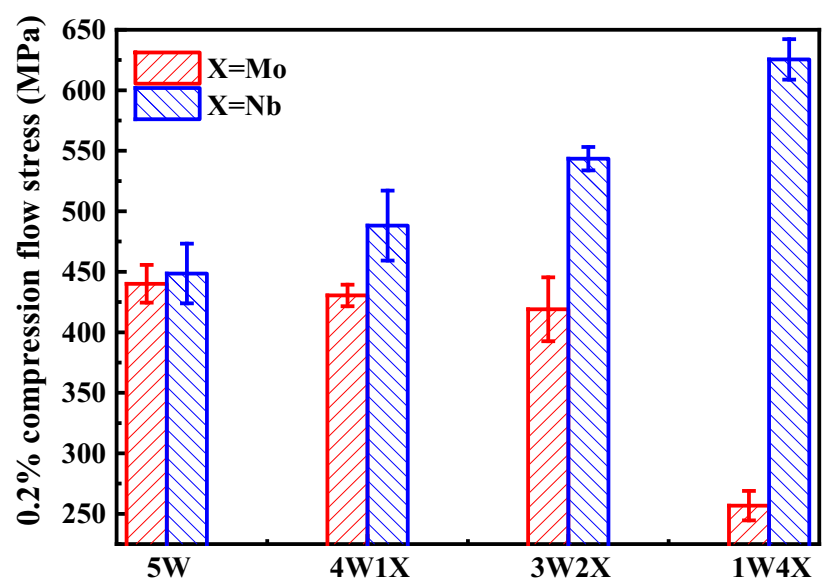

Fig. 7-Compression strength at 0.2 pct strain of the experimental alloys at $750{ }^{\circ} \mathrm{C}$.

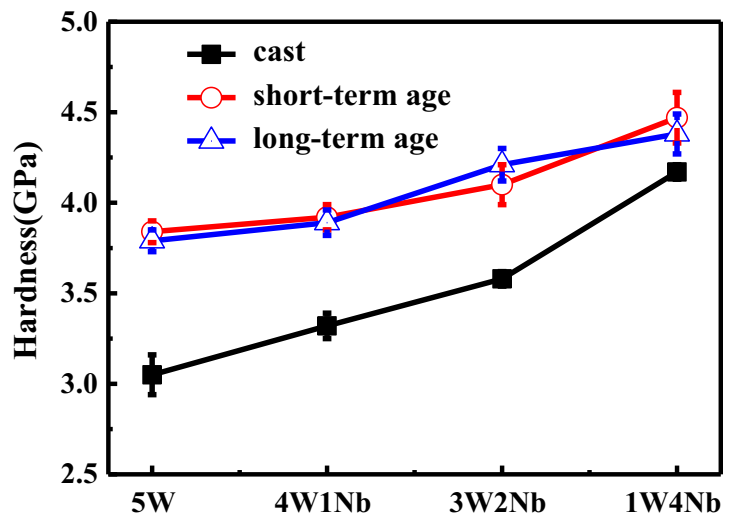

(b)

Fig. 6 - Hardness of the experimental alloys. (a) Alloys replacing $\mathrm{W}$ with $\mathrm{Mo},(b)$ alloys replacing $\mathrm{W}$ with $\mathrm{Nb}$. Short-term age: $900{ }^{\circ} \mathrm{C} /$ $24 \mathrm{~h}+750{ }^{\circ} \mathrm{C} / 12 \mathrm{~h}$, long-term age: $900{ }^{\circ} \mathrm{C} / 24 \mathrm{~h}+750{ }^{\circ} \mathrm{C} / 1000 \mathrm{~h}$. 


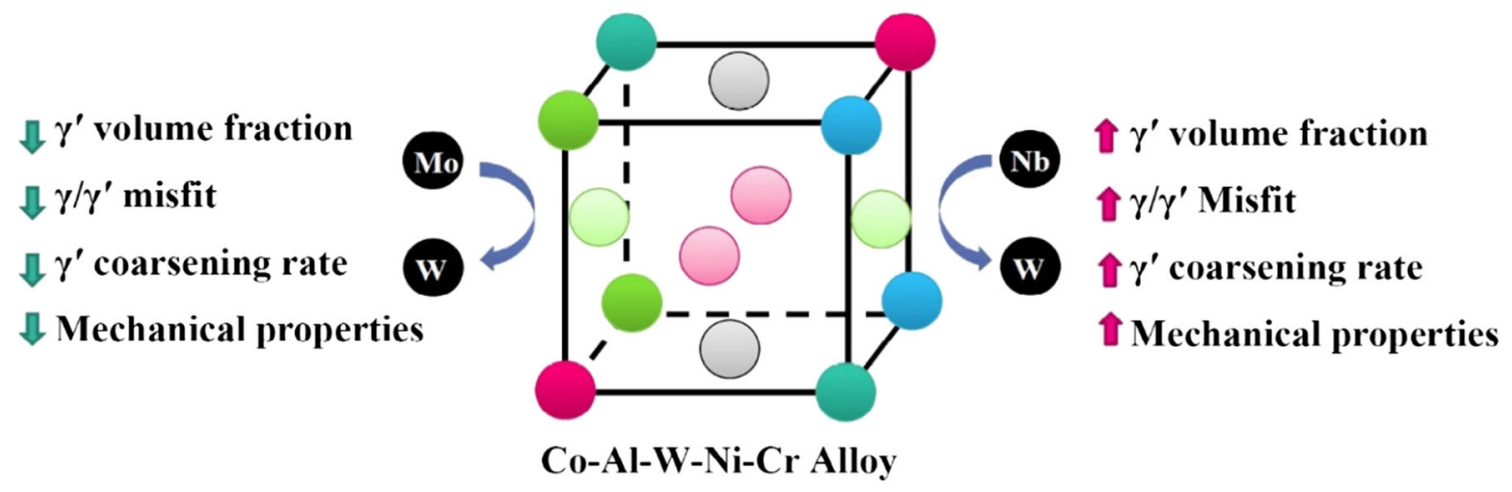

Fig. 8-The specific schemetic analysis of replacing $\mathrm{W}$ with $\mathrm{Mo}$ and $\mathrm{Nb}$.

behavior of $\gamma^{\prime}$ precipitate. As for the coherent interface for the $\gamma / \gamma^{\prime}$ two-phase interface, the interfacial energy decreases with the reduced misfit. Therefore, the smaller the $\gamma / \gamma^{\prime}$ misfits and the solutes diffusion coefficient are, the lower the coarsening rates of $\gamma^{\prime}$ precipitate may become. Whether in Co-based superalloys or Ni-based superalloys, researchers have been trying to develop the alloys with low $\gamma / \gamma^{\prime}$ two-phase misfit by adjusting alloy compositions $^{[2,3]}$ to suppress coarsening of the $\gamma^{\prime}$ phase in service environments. The shape of the $\gamma^{\prime}$ phase in nickel based superalloys is closely related to the misfit between the $\gamma / \gamma^{\prime}$ two-phases ${ }^{[4]}$ : the $\gamma^{\prime}$ phase is formed as spheres at a 0 to 0.2 pet misfit, as cubes at about 0.5 to 1.0 pet and as plates above about 1.25 pct. For the precipitates coarsening at $750{ }^{\circ} \mathrm{C}$ observed here, only the infiuence of interfacial energy and diffusing corfficient are discussed since the $\gamma^{\prime}$ volume fraction is not constant but changes significantly during aging. As is shown in Figure 4, the spherical $\gamma^{\prime}$ precipitates in the alloys containing Mo indicate that replacing $\mathrm{W}$ with $\mathrm{Mo}$ can significantly reduce the $\gamma / \gamma^{\prime}$ two-phase misfit, while the cuboidal $\gamma^{\prime}$ precipitates in alloys with $\mathrm{Nb}$ suggest $\mathrm{Nb}$ additions significantly increase it. Furthermore, the coarsening of the $\gamma^{\prime}$ phase was inhibited by the substitution of Mo for W, and is promoted by the substitution of $\mathrm{Nb}$ for $\mathrm{W}$.

To sum up, the effects of replacing $\mathrm{W}$ with Mo and $\mathrm{Nb}$ on $\gamma^{\prime}$-strengthened Co-based superalloys are systematically investigated in this study. The results show that they have different effects on the mechanical properties and microstructure stability of the alloys despite the similar influence on density reduction, as shown in Figure 8. The substitution of Mo for $\mathbf{W}$ reduces the $\gamma^{\prime}$ volume fraction, decreases the mechanical properties, suppresses the coarsening of the $\gamma^{\prime}$ phase, and reduces the $\gamma^{\prime} / \gamma^{\prime}$ two-phases misfit. Replacing $\mathrm{W}$ with $\mathrm{Nb}$ increases the $\gamma^{\prime}$ volume fraction, improves the mechanical properties, promotes the coarsening of $\gamma^{\prime}$ phase, increases the $\gamma / \gamma^{\prime}$ two-phases misfit and inhibiting the formation of $\mu$ phase. For the composition design of Co-based superalloys, it can be predicted that Mo and $\mathrm{Nb}$ may be added together to replace $\mathrm{W}$ elements to balance microstructure stability and mechanical properties.

\section{CONCLUSION}

(1) Replacing W with Mo can reduce the segregation of Al during solidification and decrease the volume fraction of $\gamma^{\prime}$ phase. The replacement of 1 at. pet $\mathrm{W}$ by 1 at. pct Mo could decrease the volume fraction of $\gamma^{\prime}$ phase by 15.0 pct in short-term aging microstructure at $750{ }^{\circ} \mathrm{C}$, and decrease the volume fraction by 8.0 pct in longterm aging microstructure up to 1000 hours.

(2) Replacing W with $\mathrm{Nb}$ can reduce the segregation of $\mathrm{Al}$ during solidification and increase the volume fraction of $\gamma^{\prime}$ phase, which indiates that the replacement of 1 at. pct $\mathrm{W}$ by 1 at. pct $\mathrm{Nb}$ could increase the volume fraction of $\gamma^{\prime}$ phase by $10.0 \mathrm{pct}$ in short-term aging microstructure at $750{ }^{\circ} \mathrm{C}$ for 12 hours, and increase the volume fraction by $8.0 \mathrm{pct}$ in long-term microstructure aged for 1000 hours.

(3) Replacing W with Mo reduces the misfit of $\gamma / \gamma^{\prime}$ two phases, and $\mu$ phase is precipitated after aging at $900{ }^{\circ} \mathrm{C} / 24 \mathrm{~h}+750{ }^{\circ} \mathrm{C} / 1000 \mathrm{~h}$. Replacing W with $\mathrm{Nb}$ increases the misfit of the $\gamma / \gamma^{\prime}$ two phases, and $\delta$ phase is formed at grain boundary after the same aging treatment.

(4) Replacing 1 at. pct W with 1 at. pct Mo reduces the density by $\sim 0.10 \mathrm{~g} / \mathrm{cm}^{3}$, reduces the Vickers hardness by $\sim 15 \mathrm{HV}$, reduces the 0.2 pct compression flow stress at $750{ }^{\circ} \mathrm{C}$ by $\sim 10 \mathrm{MPa}$. The substitutions of 1 at. pet $\mathrm{Nb}$ for 1 at. pct $\mathrm{W}$ decrease density by $\sim 0.15 \mathrm{~g} / \mathrm{cm}^{3}$, improve the Vickers hardness by $\sim 13 \mathrm{HV}$ and increases the 0.2 pct compression flow stress by $\sim 50 \mathrm{MPa}$.

\section{ACKNOWLEDGMENTS}

Authors would like to thank the financial support of National Key R\&D Program of China (No. 2017YFB0702904) and Fundamental Research Funds for the Central Universities (No. FRF-BD-17-017A). 


\section{REFERENCES}

1. J. Sato, T. Omori, K. Oikawa, I. Ohnuma, R. Kainuma, and K. Ishida: Science, 2006, vol. 312, pp. 90-91.

2. A. Bauer, S. Neumeier, F. Pyczak, and M. Göken: Scr. Mater., 2010, vol. 63, pp. 1197-1200.

3. F. Xue, M.L. Wang, and Q. Feng: Superalloys, 2012, pp. 813-21.

4. H.-Y. Yan, V.A. Vorontsov, J. Coakley, N.G. Jones, H.J. Stone, and D. Dye: Superalloys, 2012, pp. 705-14.

5. T. Omori, K. Oikawa, J. Sato, I. Ohnuma, U.R. Kattner, R. Kainuma, and K. Ishida: Intermetallics, 2013, vol. 32, pp. $274-83$.

6. L.P. Freund, S. Giese, D. Schwimmer, H.W. Höppel, S. Neumeier, and M. Göken: J. Mater. Res., 2017, vol. 32, pp. 4475-82.

7. F. Xue, H.J. Zhou, Q.Y. Shi, X.H. Chen, H. Chang, M.L. Wang, and Q. Feng: Scr. Mater., 2015, vol. 97, pp. 37-40.

8. F. Xue, H.J. Zhou, X.H. Chen, Q.Y. Shi, H. Chang, M.L. Wang, X.F. Ding, and Q. Feng: MATEC Web of Conf., 2014, vol. 14, p. 15002.

9. F.B. Ismail, V.A. Vorontsov, T.C. Lindley, M.C. Hardy, D. Dye, and B.A. Shollock: Corros. Sci., 2017, vol. 116, pp. 44-52.

10. S.A.J. Forsik, A.O.P. Rosas, T. Wang, G.A. Colombo, N. Zhou, S.J. Krnion, and M.E. Epler: Metall. Mater. Trans. A, 2018, vol. 49 A, pp. $4058-69$.

11. L. Klein, A. Bauer, S. Neumeier, M. Göken, and S. Virtanen: Corros. Sci., 2011, vol. 53, pp. 2027-34.

12. H.-Y. Yan, V.A. Vorontsov, and D. Dye: Corros. Sci., 2014, vol. 83, pp. 382-95.

13. N. Vermaak, A. Mottura, and T.M. Pollock: Corros. Sci., 2013, vol. 75 , pp. 300-08.

14. H.-Y. Yan, V.A. Vorontsov, and D. Dye: Intermetallics, 2014 vol. 48 , pp. $44-53$

15. G. Feng, H. Li, S.S. Li, and J.B. Sha: Scr. Mater., 2012, vol. 67, pp. 499-502.

16. P.J. Bocchini, C.K. Sudbrack, D.J. Sauza, R.D. Noebe, D.N. Seidman, and D.C. Dunand: Mater. Sci. Eng., A, 2017, vol. 700, pp. $481-86$.

17. M. Ooshima, K. Tanaka, N.L. Okamoto, K. Kishida, and H. Inui: J. Alloy. Compd., 2010, vol. 508, pp. 71-78.

18. F. Xue, H.J. Zhou, X.F. Ding, M.L. Wang, and Q. Feng: Mater. Lett., 2013, vol. 112, pp. 215-18.

19. S. Kobayashi, Y. Tsukamoto, and T. Takasugi: Intermetallics, 2011, vol. 19, pp. 1908-12.
20. K. Shinagawa, T. Omori, J. Sato, K. Oikawa, I. Ohnuma, R. Kainuma, and K. Ishida: Mater. Trans., 2008, vol. 49, pp. 1474-79.

21. S. Neumeier, L.P. Freund, and M. Göken: Scr. Mater., 2015, vol. 109, pp. 104-07.

22. M. Knop, P. Mulvey, F. Ismail, A. Radecka, K.M. Rahman, T.C. Lindley, B.A. Shollock, M.C. Hardy, M.P. Moody, T.L. Martin, P.A.J. Bagot, and D. Dye: JOM, 2014, vol. 66, pp. 2495-2501.

23. S.K. Makineni, B. Nithin, and K. Chattopadhyay: Scr. Mater., 2015, vol. 98, pp. 36-39.

24. S.K. Makineni, B. Nithin, and K. Chattopadhyay: Acta Mater., 2015, vol. 85, pp. 85-94.

25. C.H. Zenk, A. Bauer, P. Goik, S. Neumeier, H.J. Stone, and M. Göken: Metall. Mater. Trans. A, 2016, vol. 47A, pp. 2141-49.

26. H. Chinen, J. Sato, T. Omori, K. Oikawa, I. Ohnuma, R. Kainuma, and K. Ishida: Scr. Mater., 2007, vol. 56, pp. 141-43.

27. C.H. Zenk, I. Povstugar, R. Li, F. Rinaidi, S. Neumeier, D. Raabe, and M. Göken: Acta Mater., 2017, vol. 135, pp. 244-51.

28. J.J. Ruan, X.J. Liu, S.Y. Yang, W.W. Xu, T. Omori, T. Yang, B. Deng, H.X. Jiang, C.P. Wang, R. Kainuma, and K. Ishida: Intermetallics, 2018, vol. 92, pp. 126-32.

29. F.L.R. Tirado, J.P. Toinin, and D.C. Dunand: Acta Mater., 2018, vol. 151 , pp. $137-48$.

30. S. Antonov, W. Chen, S. Lu, D. Isheim, D.N. Seidman, Q. Feng, E. Sun, and S. Tin: Scr. Mater., 2019, vol. 161, pp. 44-48.

31. M. Chen and C.-Y. Wang: Scr. Mater., 2009, vol. 60, pp. 659-62.

32. I.M. Lifshitz and V.V. Slyozov: J. Phys. Chem. Solids, 1961, vol. 19 , pp. $35-50$.

33. S. Meher, L.J. Carroll, T.M. Pollock, and M.C. Carroll: Scr. Mater., 2016, vol. 113, pp. 185-89.

34. S. Neumeier, H.U. Rehman, J. Neuner, C.H. Zenk, S. Michel, S. Schuwalow, J. Rogal, R. Drautz, and M. Göken: Acta Mater., 2016, vol. 106, pp. 304-12.

35. S. Meher, M.C. Carroll, T.M. Pollock, and L.J. Carroll: Mater. Des., 2018, vol. 140, pp. 249-56.

36. E.W. Ross and C.T. Sims: Superalloyss II, A Wiley-Interscience Publication, New York, 1987.

Publisher's Note Springer Nature remains neutral with regard to jurisdictional claims in published maps and institutional affiliations. 